\title{
Discovering Patient Portal Features Critical to User Satisfaction: A Systematic Analysis
}

\author{
Abdullah Wahbeh \\ Slippery Rock University of PA \\ abdullah.wahbeh@sru.edu
}

\author{
Mohammad Abdel-Rahman (Al-Ramahi) \\ Texas A\&M University - San Antonio \\ mohammad.abdel@tamusa.edu \\ Tareq Nasralah \\ Dakota State University \\ tareq.nasralah@dsu.edu
}

\author{
Cherie Noteboom \\ Dakota State University \\ cherie.noteboom@dsu.edu
}

\begin{abstract}
Patient portals are consumer-centric tools that can strengthen consumers' ability to actively manage their own health and healthcare. The incorporation of patient portals provides the promise to deliver quality, low costs services to the patient population. However, patient portal adoption in large part is based on patient satisfaction. In pertaining literature, little is known about which portal features are associated with higher patient satisfaction. In this article, we extend existing literature by discovering features related to patient portal user satisfaction based on a systematic analysis of user feedback. Using MyChart, a mobile patient portal, we use text mining, $N$-Gram-based approach, to discover satisfaction features from online user reviews. We then demonstrate the performance of the features selected in predicting user satisfaction using different classifiers. Overall, the results extend existing research and highlight opportunities to improve and to enhance the design of current basic portals to improve users' satisfaction and adherence.
\end{abstract}

\section{Introduction}

Recently, the health care spending in the U.S. is becoming a major concern. The "U.S. health care spending increased 4.3 percent in 2016, reaching $\$ 3.3$ trillion or $\$ 10,348$ per person. As a share of the nation's Gross Domestic Product, health spending accounted for 17.9 percent". This national health spending number is projected to grow at an average rate of 5.5 percent per year for 2017-26, reaching $\$ 5.7$ trillion by 2026 [1]. Therefore, an intensive national effort to improve healthcare using information technology (IT) with a focus on reducing costs and increasing quality of service is well underway [2].

Technology is continuously changing and offers healthcare providers new capabilities and ways of providing healthcare. The Internet as well as electronic medical records provided new and more active role for information systems, and more specifically, patients' portals to play a role in patients' care. Patient portals consist of "provider-tethered applications that allow patients to electronically access health information [3]". They are considered a powerful consumer-centric tools that can strengthen consumers' ability to actively manage their health and healthcare. Patient portals are positioned as a central component of patient engagement through the potential to change the physician-patient relationship and enable chronic disease self-management [4]. Patient portals can lead to improvements in clinical outcomes, patient behavior, and experiences [5]. They provide patients with the ability to access personal medical records, schedule electronic visits, receive virtual care, and realtime video visits. The incorporation of patient portals provides the promise to deliver excellent quality, at optimized costs, while improving the health of the population.

In literature, the benefits of patient portals as health information technology have been widely studied. However, such benefits do not come without its challenges, namely maintaining patient satisfaction with such technology. Nowadays, patient satisfaction is considered a health care quality measure by health care providers and regulators $[6,7]$. Patient satisfaction, an individual's evaluation of his or her health-care experience, is becoming increasingly important in the healthcare industry [8]. In addition, it is increasingly becoming a major factor in the effectiveness of care, and has been established to measure the success of services provided by the care provider [9]. From a patient point of view, the degree of satisfaction is a judgment on the quality of care provided [10]. On the other hand, a provider view of satisfaction reflect the patient's level of engagement and participation in care [11].

Even though satisfaction has been an important healthcare quality measure and has been the focus of many studies in literature, satisfaction is still not easy to characterize $[12,13]$. The adoption of satisfaction as a quality indicator is associated with well-known 
measurement problem [6, 14]. Some well-developed and validated measures exist, however, many studies use poorly developed measures and instruments, which can lead to biased and inaccurate results regarding patient satisfaction $[15,16]$.

Large studies in outpatient settings have found that providing patients with adequate functionalities leads to increases in patient satisfaction and then adherence to patient portal [4]. However, little is known about the different patient portal characteristics that are associated with higher patient satisfaction. While there is some evidence that patient portal as Health Information Technology (HIT) improves patient satisfaction, studies were not consistent with their findings [17]. It seems there is insufficient evidence to support how portals empower patients and improve quality of care. Existing studies rarely analyzed a full patient portal, and only focused on specific features such as secure messaging, as well as disease management and monitoring [18]. Overall, access to information and secure messaging are probably one facet of patient satisfaction; it is, therefore, questionable whether the impact of a patient portal on patient satisfaction is measurable [19]. Thus, there is a need for further research that focuses on use of the patient portal and measures of patient satisfaction [18, 20].

Nowadays, the advances in Web 2.0 technologies have enabled consumers to easily and freely exchange opinions on products and services on an unprecedented scale (volume) and in real time (velocity). Online user reviews provide us with one of the most powerful channels for extracting user feedback that can help measure and better understand patient satisfaction. Analyzing users' reviews from actual use has the potential to greatly inform developers of patients' actual experiences and provide a window into ways to improve care delivery and patient satisfaction [21]. However, up to now, very few efforts have been made to extract knowledge from large-scale online reviews of a patient portal to help understand patient satisfaction and its antecedents.

The objective of this study is to systematically analyze users' reviews of mobile patient portal to:

- Discover features that are associated with patient satisfaction

- Test features selected in predicting user satisfaction using different classifiers

The main contributions of this research are threefolds:

1- From a methodological perspective, this research presents a novel approach to analyze user reviews. Specifically, $n$-gram-based text mining technique to discover features associated with user satisfaction from online user-generated contents.

2- This research adds to the patient portal knowledge base new features that have impact on user satisfaction as well as provides support to some existing features.

3- Last but not least, the findings of this research provide developers with insights into the userreported issues of mobile patient portal app and suggestions to influence patient satisfaction.

\section{Literature Review}

In literature, a number of predictors that influence patient satisfaction has been studied. Jackson, et al. [12] studied patient satisfaction with medical care and concluded that specific communication barriers as well as unmet patient expectations decrease patient satisfaction. Brédart, et al. [22] studied a number of characteristics that influence patient satisfaction such as patient-provider communication, technical quality, waiting time, factors related to payments, continuity of provider/location of care, physical environment, and availability of medical care resources. Ahmad, et al. [23] studied factors influencing patient satisfaction and concluded that accessibility and availability of medical services influence patient satisfaction. Waters, et al. [24] studied factors related to patent satisfaction using a cross-sectional, qualitative design and concluded that waiting/contact time, trust, empathy, communication, expectation and relatedness influence patient satisfaction

In the literature, few studies have addressed the relationship between the use of patient portals and patients' satisfaction. Ford, et al. [25] have assessed the relationship between the quality of hospitals' public websites and their aggregated patient satisfaction ratings. The primary data (Website characteristics) and secondary data (American Hospital Association (AHA) annual survey database) were collected from 1,952 facilities. Linear regression used to evaluate the existence of the relationship and finding showed that the hospitals' website quality is related to the consumers' willingness to recommend the facility. Also, the hospital websites were not being effectively used to link patients directly to caregivers. Finally, the use of website quality as an indicator of overall care quality is consistent with the idea that greater organizational transparency will lead to improved care quality outcomes. Osborn, et al. [26] have characterized and evaluated the design of patient web portals to improve health care processes and outcomes in diabetes. The paper followed a systematic literature review research methodology. The finding showed that patient web portals have a positive impact on patient 
outcomes, patient-provider communication, disease management, and access to health care, as well as patient satisfaction with health care. Ralston, et al. [27] have described the evolution, use, and user satisfaction of a patient Web site providing a shared medical record between patients and health professionals. The authors conducted a retrospective, serial, cross-sectional study. Data were collected using a satisfaction survey. Findings showed that the use and satisfaction with patient web portal were greatest for accessing services and information involving ongoing, active care and patient-provider communication. Also, patients reported the highest satisfaction with medication refills, patient-provider messaging, and medical test results.

Other studies in the literature have addressed the relationship between one aspect or feature of a patient Web portal and patients' satisfaction. Abanes and Adams [28] have investigated the use of a Web-based patient-provider messaging system to increase patient satisfaction in the psychiatric outpatient clinic. Data were collected retrospectively on satisfaction scores from surveys before implementation and after implementation. Comparative analysis and descriptive statistics were presented. Patients reported overall satisfaction using a secure on-line communication system with providers. Also, patients were satisfied with the Web-based messaging system more than using the phone system. Wade-Vuturo, et al. [29] have assessed the use and benefits from secure messaging within a Web portal using focus group and survey. The analysis from the focus group transcripts identified the benefits and barriers to using secure messaging within Web portal. Reported benefits from using the secure messaging included enhanced patient satisfaction and enhanced efficiency. Kruse, et al. [18] conducted a systematic literature review to understand the effect of patient portal on quality outcomes. Analysis showed that several studies evaluated the use of the secure messaging feature of a patient portal. Majority of the studies demonstrated a high level of patient satisfaction with such feature. In another systematic literature review study; medication refills, secure patientprovider messaging, and medical test results have been associated with higher degrees of patient satisfaction [30].

Following a systematic literature review, Liu, et al. [31] evaluated patient satisfaction as well as other factors with electronic medical records. The study reported many factors that influence patient satisfaction with electronic medical records such as patient characteristics and sociotechnical factors, contextual factors, and technical issues. In addition, Sorondo, et al. [32] have evaluated the use of a patient portal within primary care practices and evaluated the potential workflow implications using quantitative and qualitative measures of patient adoption, provider adoption, workflow impact, financial impact, and technology impact. The results showed that patients expressed satisfaction with the portal, as it allows them to view their information. Finally, Neuner, et al. [33] reported the experience with a commercial patient portal. The logistic regression model was used to examine factors associated with surveyed patients' satisfaction. Results showed that patients' satisfaction is related to different patient portal features, where the greater satisfaction was with secure messaging. Age was not associated with satisfaction or likelihood of portal recommendations. Table 1 summarizes findings from other relevant studies that have addressed patients' portal potentials and their relationships with other relevant factors including patients' satisfaction.

Table 1. Summary of Literature

\begin{tabular}{|l|l|l|l|}
\hline Article & Objective & Methodology & Findings \\
\hline $\begin{array}{l}\text { Amante, et al. } \\
{[34]}\end{array}$ & $\begin{array}{l}\text { Identify barriers and } \\
\text { facilitators to using } \\
\text { patient portal }\end{array}$ & $\begin{array}{l}\text { Systematic } \\
\text { literature review }\end{array}$ & $\begin{array}{l}\text { Barriers included a lack of patient capacity, } \\
\text { desire, and awareness of portal/portal functions, } \\
\text { patient capacity, lack of provider and patient } \\
\text { buy-in to portal benefits, and negative patient } \\
\text { experiences using portals. Facilitators of portal } \\
\text { enrollment and utilization were providers and } \\
\text { family members recommending and engaging in } \\
\text { portal use }\end{array}$ \\
\hline $\begin{array}{l}\text { Mishuris, et } \\
\text { al. [35] }\end{array}$ & $\begin{array}{l}\text { Identify barriers to and } \\
\text { facilitators of using } \\
\text { patient portal }\end{array}$ & $\begin{array}{l}\text { Qualitative study - } \\
\text { content analysis } \\
\text { knive themes identified including limited } \\
\text { limited computer and internet access, desire to } \\
\text { learn more, and value of surrogates }\end{array}$ \\
\hline $\begin{array}{l}\text { Otte-Trojel, et } \\
\text { al. [5] }\end{array}$ & $\begin{array}{l}\text { Examine how patient } \\
\text { portals contribute to } \\
\text { health service delivery } \\
\text { and patient outcomes }\end{array}$ & $\begin{array}{l}\text { Realist review } \\
\text { method }\end{array}$ & $\begin{array}{l}\text { Patient portals can lead to improvements in } \\
\text { clinical outcomes, patient behavior, and } \\
\text { experiences }\end{array}$ \\
\hline
\end{tabular}




\begin{tabular}{|c|c|c|c|}
\hline $\begin{array}{l}\text { Sorondo, et } \\
\text { al. [36] }\end{array}$ & $\begin{array}{l}\text { Assess whether patient } \\
\text { portals influence patients' } \\
\text { ability for self- } \\
\text { management, improve } \\
\text { overall health, and reduce } \\
\text { healthcare utilization }\end{array}$ & $\begin{array}{l}\text { Quasi- } \\
\text { experimental pre- } \\
\text { post study design }\end{array}$ & $\begin{array}{l}\text { Portals may improve access to providers and } \\
\text { health data that lead to improvements in } \\
\text { patients' functional status and reduce high-cost } \\
\text { healthcare utilization, but it does not improve } \\
\text { self-efficacy, the perception of health state, or } \\
\text { experience with primary care practices }\end{array}$ \\
\hline $\begin{array}{l}\text { Kruse, et al. } \\
{[18]}\end{array}$ & $\begin{array}{l}\text { Summarize results the } \\
\text { effect of patient portals } \\
\text { on quality, or chronic- } \\
\text { condition outcomes, and } \\
\text { its implications for } \\
\text { Meaningful Use }\end{array}$ & $\begin{array}{l}\text { Systematic } \\
\text { literature review }\end{array}$ & $\begin{array}{l}\text { Very few studies associated use of the patient } \\
\text { portal, or its features, to improved outcomes. } \\
\text { Other studies reported improvements in } \\
\text { medication adherence, disease awareness, self- } \\
\text { management of disease, a decrease of office } \\
\text { visits, and increase in quality regarding patient } \\
\text { satisfaction and customer retention }\end{array}$ \\
\hline $\begin{array}{l}\text { Ammenwerth, } \\
\text { et al. [19] }\end{array}$ & $\begin{array}{l}\text { Address the impact of } \\
\text { electronic patient portals } \\
\text { on patient care }\end{array}$ & $\begin{array}{l}\text { Systematic } \\
\text { literature review }\end{array}$ & $\begin{array}{l}\text { Insufficient evidence to support how portals } \\
\text { empower patients and improve quality of care. } \\
\text { Also, access to information is probably only one } \\
\text { facet of patient satisfaction }\end{array}$ \\
\hline $\begin{array}{l}\text { Goldzweig, et } \\
\text { al. [30] }\end{array}$ & $\begin{array}{l}\text { Systematically review the } \\
\text { literature reporting the } \\
\text { effect of patient portals } \\
\text { on clinical care }\end{array}$ & $\begin{array}{l}\text { Systematic } \\
\text { literature review }\end{array}$ & $\begin{array}{l}\text { Medication refills, secure patient-provider } \\
\text { messaging, and medical test results have been } \\
\text { associated with higher degrees of patient } \\
\text { satisfaction }\end{array}$ \\
\hline $\begin{array}{l}\text { Neuner, et al. } \\
\text { [33] }\end{array}$ & $\begin{array}{l}\text { Reports the experience } \\
\text { with adoption of a } \\
\text { commercial patient portal }\end{array}$ & $\begin{array}{l}\text { Portal use metrics } \\
\text { and a patient } \\
\text { survey }\end{array}$ & $\begin{array}{l}\text { Satisfaction with the portal overall and with } \\
\text { portal-based e-mails was high. Also, Less than } \\
\text { half of respondents reported being very satisfied } \\
\text { with patient education }\end{array}$ \\
\hline $\begin{array}{l}\text { Ralston, et al. } \\
\text { [37] }\end{array}$ & $\begin{array}{l}\text { Describe the evolution, } \\
\text { use, and satisfaction of a } \\
\text { patient Web portal }\end{array}$ & $\begin{array}{l}\text { Retrospective } \\
\text { analysis of portal } \\
\text { use from server } \\
\text { logs }\end{array}$ & $\begin{array}{l}\text { Enrollees reported highest satisfaction for } \\
\text { medication refills, patient provider messaging, } \\
\text { and medical test results }\end{array}$ \\
\hline $\begin{array}{l}\text { Tannery, et } \\
\text { al. [38] }\end{array}$ & $\begin{array}{l}\text { Measure the usefulness } \\
\text { and impact of a portal } \\
\text { (Clinical Focus) }\end{array}$ & $\begin{array}{l}\text { Questionnaire / } \\
\text { Surveys }\end{array}$ & $\begin{array}{l}\text { A high percentage of the respondents agreed or } \\
\text { strongly agreed that Clinical Focus met their } \\
\text { expectations, and most of them were satisfied } \\
\text { using Clinical Focus }\end{array}$ \\
\hline $\begin{array}{l}\text { Tuil, et al. } \\
\text { [39] }\end{array}$ & $\begin{array}{l}\text { Review the impact of } \\
\text { electronic patient portals } \\
\text { on patient empowerment }\end{array}$ & $\begin{array}{l}\text { Systematic } \\
\text { literature review }\end{array}$ & $\begin{array}{l}\text { Although the personal health record was } \\
\text { frequently used, and its users were satisfied with } \\
\text { the functions offered by the website, there was } \\
\text { no increase in patient satisfaction regarding the } \\
\text { delivered care }\end{array}$ \\
\hline $\begin{array}{l}\text { Schnipper, et } \\
\text { al. [40] }\end{array}$ & $\begin{array}{l}\text { Describe the background, } \\
\text { design, and preliminary } \\
\text { results of a patient portal }\end{array}$ & $\begin{array}{l}\text { Quantitative } \\
\text { analysis } \\
\text { (statistics) }\end{array}$ & $\begin{array}{l}\text { Usage and satisfaction data indicate that patients } \\
\text { found the module easy to use, provides more } \\
\text { accurate information, and enable them to be } \\
\text { more prepared for their forthcoming visits }\end{array}$ \\
\hline $\begin{array}{l}\text { Johnson, et al. } \\
\text { [41] }\end{array}$ & $\begin{array}{l}\text { Investigate } r \text { patient } \\
\text { preferences concerning } \\
\text { online access to } \\
\text { radiologic reports }\end{array}$ & $\begin{array}{l}\text { Scenarios } \\
\text { quantitative } \\
\text { analysis }\end{array}$ & $\begin{array}{l}\text { Majority of participants preferred the portal } \\
\text { method of notification over ways they have } \\
\text { historically gotten results, with an increased } \\
\text { proportion being satisfied with it overall }\end{array}$ \\
\hline
\end{tabular}

\section{Method}

\subsection{Data collection}

In this study, our target population is mobile patient portal users. The patient portal selected as the empirical setting of this research is Epic's MyChart.
We selected this patient portal for study as Epic is replacing other vendors in the EHR market and is beginning to establish a single vendor landscape. Reportedly, Epic has at least partial health information for over $51 \%$ of the US population [42]. MyChart mobile app is available for Apple and Android devices. The data were collected from Apple iTunes store and Play store, where the online reviews posted by the 
users were gathered using APIs. We developed a web crawler to collect data automatically. Through this process, we obtain our data set consisting of 3475 reviews.

To examine the predictors of users' satisfaction, we focus only on low rating (i.e., 1 and 2-star) and high rating (i.e., 4 and 5-star) user reviews. Hence, we remove those neutral reviews (i.e., 3-star) from the data set resulting with 2995 reviews distributed as 1165 low rating reviews and 1830 high rating reviews. Since users tend to write high rating reviews when they are satisfied and low rating reviews when they are not, we divide the data set into two classes, satisfied corresponds to 4 and 5-star user reviews and unsatisfied corresponds to 1 and 2 -star reviews.

\subsection{Word-Level N-Gram Representation}

A straight-forward approach for representing text as feature vectors is the set-of-words approach. In this approach, "if a word occurs in a particular document, its corresponding attribute is set to 1 , if not it is set to 0" [43]. A more generalized approach of the set-ofwords is called $n$-grams. In text categorization, textual data can be represented using $\underline{n}$-grams - a sequences of words of length $n$. $\underline{N}$-grams transforms documents into high dimensional feature vectors where each feature corresponds to a substring of length $n$.

In this work, we used a word-level $n$-gram representation for users' reviews. To do that, when preprocessing the data, we removed stop words and represented user reviews using vectors of word-level $n$ grams weights. Specifically, the weight of a particular $n$-gram in a user review is the frequency of the n-gram in the user review and is 0 otherwise. For the word ngrams, we use range from 1 to 3 (i.e., we include unigram (one word), bigrams (two words), and trigrams (three words)). For example, ' results', ' lab results', and ' check test results' are examples of unigram, bigram and trigram respectively. The reason we select word-level $n$-grams features to represent user reviews over bag-of-words features is that the latter has two major weaknesses: 1) they lose the ordering of the words and 2) they ignore semantics of the words [44].

A problem with representing user reviews as vectors of $n$-grams is the large number of features obtained. In our case, the number of the $n$-grams generated from our data set is 50951. If we use all the $n$-grams as features, such many features can potentially cause the issue of overfitting. We hence perform feature selection using the commonly used Chi-square $\left(\mathrm{X}^{2}\right)$ method. The Chi-square method evaluates features individually by measuring their Chi-square statistic with respect to the classes of the target variable (i.e., user satisfaction). We use only the features that have a Chi-square test score that is statistically significant at the 0.05 level (i.e., p-value<0.05). As a result, we obtained 682 features that are statistically significant with our dependent variable user satisfaction. Since feature selection must be performed using only training data, we randomly split our data set into $70 \%$ training and $30 \%$ testing partitions and use only the training data set for feature selection and test data for evaluation.

\subsection{Evaluation Metrics}

To evaluate the predictive power of the features selected, we chose four evaluation metrics, precision, recall, accuracy, and F1 Score. The precision metric evaluates the prediction accuracy by dividing the number of positive samples that correctly predicted as positive (TP) on the total number of both TP and those mistakenly classified as positive (FP). Note that the drawback of the precision is that it does not account for those who are incorrectly classified as negative samples.

$$
\text { Precision }=\mathrm{TP} /(\mathrm{TP}+\mathrm{FP})
$$

On the other hand, the recall metric evaluates the prediction accuracy by dividing the number of TP on the total number of both TP and those are incorrectly classified as negative (FN).

Recall $=\mathrm{TP} /(\mathrm{TP}+\mathrm{FN})$

The accuracy metric measures the percentage of those correctly classified as positive or negative examples.

$$
\text { Accuracy }=(\mathrm{TP}+\mathrm{TN}) /(\mathrm{TP}+\mathrm{TN}+\mathrm{FP}+\mathrm{FN}) \ldots(3)
$$

The last metric is F1 score. F1 Score is the weighted average of Precision and Recall. Therefore, this score takes both false positives and false negatives into account.

F1 Score $=2 *($ Recall $*$ Precision $) /($ Recall + Precision) .... (4)

\section{Results and Discussions}

\subsection{Features selected}

We discovered a total of 682 features. Table 2 shows a sample of features discovered. These features are mainly related to the integration with health apps, security (log in issues), ability to communicate with health providers, reminders, schedule appointments, 
the ability to access information, view medical records, view medications, check test results, order prescription refills and ease of use of the patient portal.

Table 2: Sample of features discovered

\begin{tabular}{|l|l|}
\hline $\begin{array}{l}\text { Integration with } \\
\text { health apps }\end{array}$ & 'health systems', 'healthkit' \\
\hline Security & $\begin{array}{l}\text { 'secure connection', 'security' } \\
\text { 'security error', 'password } \\
\text { function' }\end{array}$ \\
\hline $\begin{array}{l}\text { Communication } \\
\text { with health } \\
\text { providers }\end{array}$ & $\begin{array}{l}\text { 'communicate doctor', 'doctor } \\
\text { responds' }\end{array}$ \\
\hline Reminders & 'reminders', 'notification', \\
\hline $\begin{array}{l}\text { Schedule } \\
\text { appointments }\end{array}$ & $\begin{array}{l}\text { 'app schedule appointments', } \\
\text { 'appointments', 'make } \\
\text { appointment app' }\end{array}$ \\
\hline $\begin{array}{l}\text { Access medical } \\
\text { records }\end{array}$ & $\begin{array}{l}\text { 'check test results', 'lab', 'lab } \\
\text { results', 'medication' } \\
\text { 'medications', 'prescription } \\
\text { refills', 'prescriptions', 'refills' }\end{array}$ \\
\hline $\begin{array}{l}\text { Usefulness and ease } \\
\text { of use }\end{array}$ & $\begin{array}{l}\text { 'easy use love', 'great app easy', } \\
\text { 'useful app' }\end{array}$ \\
\hline
\end{tabular}

4.1.1 Integration. Patient portal users expressed their need to have patient portal app integrated with health apps as stated by this user review "The MyChart app should integrate with Health on iOS. Ideally, lab results would be sourced from MyChart and feed into Apple's Health iOS". Users also reported some security issues such as lack of password integration and touch ID feature as stated in these user reviews respectively, "this app does not have password integration yet. I use 1Password. I should be able to access it from the login screen", "Would love to see Touch ID integrated for login", "Another nicety would to allow integration to mobile device's biometric security authentication components"

4.1.2 Communication. Other features reported by MyChart users are mainly related to the functionalities provided and supported by the application. Patientprovider communication is one of the features reported by those who were satisfied by MyChart. For example, many users stated that "Works great for communication with providers", "This is so easy to use and it makes communication with my doctors a breeze", "I use it mostly for communication with my doctor and her staff'. Patient-Provider communication has been reported as one of the most important factors related to patient satisfaction with patient portal $[22$, 24, 26].

4.1.3 Reminders. The ability to receive reminders is also related to patient satisfaction with MyChart use. Many users reported that MyChart provides the ability to set reminders and receive notification regarding different aspects of care delivery. For example, "Must have! Ask your Dr if they have it. Then you can receive notes and health reminders from Dr", "Awesome app Makes doctor's appointment and reminders easy and convenient", "It works perfectly and sends reminders to me automatically".

4.1.4 Schedule appointments. The ability to schedule appointments is a factor related to patient satisfaction with MyChart use. Satisfied users stated that they can schedule appointment with provider through the application conveniently and easily. For example, some users stated, "I was able to message and make a sooner appointment than I could on their website which is cool", "No problems scheduling appointments or contacting docs", "App is great! Could use an option to be able to schedule appointments as well!!", and "It's very helpful it's easy to use for making appointment".

4.1.5 Access medical records. Access to information and the ability to view medical records is another factor related to patient satisfaction with MyChart. Many users stated that "Great to be able to access information from most of my doctors in one place", "Helps to access my med record", "Love that I have access to my medical files!", and "Great way to contact my Dr or access my info". This matches the findings by Ammenwerth, Schnell-Inderst [19] who stated that access to information is one facet of patient satisfaction. The users also reported the ability to check test results as an important feature of MyChart. Many satisfied users of MyChart stated that "I like that I can see my family's appointments and test results", "I like that I get test results back faster and with explanations included", "I can see my test results talk to my doctor and schedule appointments", and "It's been helpful to be able to read your test results and the appointment reminders". This is consistent with literature where patients reported higher level of satisfaction with patient portals that allow patients to view their test results $[30,37]$. The ability to view medication and related information is related to patient satisfaction. Many users stated that "manage medication at my convenience", "test results and medication lists are added advantages", "It shows test results medication and you could do refills as well", "I love this app it's important to keep track of all medications", "Love this app it's so easy to find my daughter medication and all info". The ability to order prescription/medication refills has also been reported as one of the features related to patient satisfaction with patient portal. Many users stated that "very useful for accessing health info, prescriptions and requesting refills", "I love this cause 
I don't have to wait for an appointment for refills are wait to see results", and "Medication refills and scheduling appointments so much more convenient and easier now!'”. This finding matches the existing literature where portal users reported highest satisfaction for medication refills [27, 30].

4.1.6 Usefulness and ease of use. Ease of use is reported by the users who are satisfied with using MyChart. Some users reported that the application is easy to use "Easy to use, simple and straight forward", "Easy to use and friendly", "Satisfied. So super excited. Makes life easy". This matches the finding by Schnipper, Gandhi [40] who found that patient satisfaction is related to the portal ease of use. Usefulness is another feature that is directly related to patient satisfaction with the portal. Some users reported that MyChart is very useful and make them satisfied. For example, "This App has been very useful to me and my little one! Couldn't be more satisfied", "It shows useful information", "This chart is very useful for reevaluating what is wrong with me". This matches the findings by Tannery, Epstein [38] who measured the usefulness and impact of patient portal and found that the portal met their expectations, and most of them were satisfied using it.

\subsection{Comparison with Pertaining Literature}

When comparing our results with pertaining literature, we can find intersections points in some features. For example, communication related features could be mapped to "patient-provider communication", "patient-provider messaging" [27], and "a secure on-line communication system with providers" [28, 29, 33] features in literature. Similarly, "check test results" feature corresponds "view patients' information" [32]. Therefore, our findings demonstrate existing features in literature. However, our results are obtained from analysis of user feedback of actual use of mobile patient portal rather than survey or interview data.

\subsection{Predictive Power of the Features Discovered}

Table 3 shows the performance results of the features discovered in predicting user satisfaction using different classifiers. Classifiers used include decision tree, linear SVC, logistic regression, and random forest.
Table 3: Performance Results

\begin{tabular}{|l|c|c|c|c|}
\hline \multirow{2}{*}{ Classifier } & \multicolumn{4}{|c|}{ Metric } \\
\cline { 2 - 5 } & Accuracy & F1 & Precision & Recall \\
\hline $\begin{array}{l}\text { Decision } \\
\text { Tree }\end{array}$ & 0.82 & 0.77 & 0.76 & 0.78 \\
\hline $\begin{array}{l}\text { Linear } \\
\text { SVC }\end{array}$ & 0.84 & 0.78 & 0.73 & 0.84 \\
\hline $\begin{array}{l}\text { Logistic } \\
\text { Regression }\end{array}$ & 0.87 & 0.83 & 0.80 & 0.87 \\
\hline $\begin{array}{l}\text { Random } \\
\text { Forest }\end{array}$ & 0.85 & 0.81 & 0.81 & 0.81 \\
\hline
\end{tabular}

Logistic Regression achieved the highest accuracy with a value of 0.8721 followed by Random Forest with a value of 0.8498 , Linear SVC with a value of 0.8387, and finally, Decision Tree with a value of 0.8220. The Logistic Regression also achieved the highest F1 measure with a value of 0.8321 followed by Random Forest and Linear SVC with values 0.8107 and 0.7820 respectively. Finally, the Decision Tree achieved a value of 0.0 .7734 .

With respect to precision, the Random Forest achieved the highest score with a value of 0.8095 followed by Logistic Regression with a value of 0.7983. Decision Tree achieved a value of 0.7647 followed by Linear SVC with the lowest value of 0.7283. Finally, Logistic Regression achieved the highest recall with a value of 0.8689 followed by Linear SVC and Random Forest with values 0.8442 and 0.8118 respectively. Decision Tree achieved the lowest value of 0.7822 .

\section{Conclusion}

This study aims to systematically analyze usergenerated contents of patient portal and discover the features that can predict user satisfaction. We adopt a text mining-based approach to leveraging online user reviews as a primary data source. To demonstrate the predictive power of the features discovered, we run different classifiers.

Overall, the findings revealed predictors of user satisfaction of patient portal namely, allowing patients to schedule and track appointments, supporting touch ID functionality so patients can log in using their fingerprints, providing patients with access to their information such as medications, office visits, prescriptions, and test results, and support reminders/notifications as well as provide secured communications between health providers and patients (i.e., patient-provider messaging) leads to increases in patient satisfaction and then adherence to patient portal. Patient portals should enable patients to 
communicate their readings and information with physicians.

Further, the findings of the study highlight the importance of integrating users with other health apps in their usage context (i.e., Apple HealthKit) as well as remind users of their target behavior to help them stay on track.

Overall, the contribution of this work can be described along two dimensions: empirical and practical. The empirical contribution of this work is to show the potential of data mining techniques in identifying important mobile apps' features related to increased patient satisfaction. On the other hand, the practical contribution is an attempt to show that such method and identified features can help teams develop and design mobile apps that could potentially possess higher level of acceptance and usage by the users.

Limitations of this research are related to the generalizability of the features discovered. The selected reviews are based on a single patient portal application (i.e., MyChart) from Apple and Google Play Stores. There is a need to extend the dataset to include reviews from other mobile patient portal applications.

\section{References}

1. CMS. National Health Expenditure Projections 2017-2026. 2016 [cited 2018 May 20]; Available from: https://www.cms.gov/Research-StatisticsData-and-Systems/Statistics-Trends-andReports/NationalHealthExpendData/Downloads/Fo recastSummary.pdf.

2. Yaraghi, N., The benefits of health information exchange platforms: measuring the returns on a half a billion dollar investment. 2015: Center for Technology Innovation at Brookings.

3. Agha, L., The effects of health information technology on the costs and quality of medical care. Journal of health economics, 2014. 34: p. 1930.

4. McAlearney, A.S., et al., High Touch and High Tech (HT2) Proposal: Transforming Patient Engagement Throughout the Continuum of Care by Engaging Patients with Portal Technology at the Bedside. JMIR Research Protocols, 2016. 5(4).

5. Otte-Trojel, T., et al., How outcomes are achieved through patient portals: a realist review. Journal of the American Medical Informatics Association, 2014. 21(4): p. 751-757.

6. Ross, C.K., C.A. Steward, and J.M. Sinacore, A comparative study of seven measures of patient satisfaction. Medical care, 1995.

7. Nurumal, M.S., et al., Satisfaction levels of clients using emergency medical service in Klang Valley: retrospective telephone survey. Malaysian Journal of Public Health Medicine, 2016. 16(3): p. 295299.
8. Shirley, E.D. and J.O. Sanders, Patient satisfaction: implications and predictors of success. JBJS, 2013. 95(10): p. e69.

9. Lyngkhoi, R. and G. Brindha, A study on patient satisfaction of outpatient department. Indian Journal of Science and Technology, 2015. 8(32).

10. Kaya, S.D., Y.Y. Ileri, and A. Yuceler, Importance of hospital way-finding system on patient satisfaction, in Business Challenges in the Changing Economic Landscape-Vol. 2. 2016, Springer. p. 33-40.

11. Ndifon, L., J.E. Edwards, and L. Halawi, Impact of Electronic Health Records On Patient Outcomes. Issues in Information Systems, 2016. 17(4): p. 187.

12. Jackson, J.L., J. Chamberlin, and K. Kroenke, Predictors of patient satisfaction. Social science \& medicine, 2001. 52(4): p. 609-620.

13. Kalaja, R. and R. Myshketa, Socio demographic variables' impact on hospitalized patient satisfaction in Albania. Journal of Process Management. New Technologies, 2016. 4(1): p. 48-54.

14. Nieman, C.L., et al., Whose experience is measured?: a pilot study of patient satisfaction demographics in pediatric otolaryngology. The Laryngoscope, 2014. 124(1): p. 290-294.

15. Barnett, S.F., et al., Patient-Satisfaction Measures in AnesthesiaQualitative Systematic Review. Anesthesiology: The Journal of the American Society of Anesthesiologists, 2013. 119(2): p. 452478.

16. Roham, M., A.R. Gabrielyan, and N.P. Archer, Predicting the impact of hospital health information technology adoption on patient satisfaction. Artificial intelligence in medicine, 2012. 56(2): p. 123-135.

17. Rozenblum, R., et al., The impact of medical informatics on patient satisfaction: a USA-based literature review. International journal of medical informatics, 2013. 82(3): p. 141-158.

18. Kruse, C.S., K. Bolton, and G. Freriks, The effect of patient portals on quality outcomes and its implications to meaningful use: a systematic review. Journal of medical Internet research, 2015. 17(2).

19. Ammenwerth, E., P. Schnell-Inderst, and A. Hoerbst, The impact of electronic patient portals on patient care: a systematic review of controlled trials. Journal of medical Internet research, 2012. 14(6).

20. Dumitrascu, A.G., et al., Patient portal use and hospital outcomes. Journal of the American Medical Informatics Association, 2017.

21. Minemyer, P. Hospitals can use patient reviews to improve healthcare. 2017 [cited 2017 Nov 20]; Available from:

https://www.fiercehealthcare.com/patientengagement/take-advantage-patient-reviews-toimprove-healthcare.

22. Brédart, A., et al., Quality of care in the oncology outpatient setting from patients' perspective: a 
systematic review of questionnaires' content and psychometric performance. Psycho-Oncology, 2015. 24(4): p. 382-394.

23. Ahmad, A.M.K., et al., Factors influencing patient satisfaction with pharmacy services: An empirical investigation at king fahd armed forces hospital, Saudi Arabia. International Journal of Business and Management, 2016. 11(9): p. 272.

24. Waters, S., et al., Identification of factors influencing patient satisfaction with orthopaedic outpatient clinic consultation: A qualitative study. Manual therapy, 2016. 25: p. 48-55.

25. Ford, E.W., et al., Patient satisfaction scores and their relationship to hospital website quality measures. Health marketing quarterly, 2013. 30(4): p. 334-348.

26. Osborn, C.Y., et al., Patient web portals to improve diabetes outcomes: a systematic review. Current diabetes reports, 2010. 10(6): p. 422-435.

27. Ralston, J.D., et al., Patient web services integrated with a shared medical record: patient use and satisfaction. Journal of the American Medical Informatics Association, 2007. 14(6): p. 798-806.

28. Abanes, J.J. and S. Adams, Using a web-based patient-provider messaging system to enhance patient satisfaction among active duty sailors and marines seen in the psychiatric outpatient clinic: A pilot study. Nursing Clinics of North America, 2014. 49(1): p. 91-103.

29. Wade-Vuturo, A.E., L.S. Mayberry, and C.Y. Osborn, Secure messaging and diabetes management: experiences and perspectives of patient portal users. Journal of the American Medical Informatics Association, 2012. 20(3): p. 519-525

30. Goldzweig, C.L., et al., Electronic patient portals: evidence on health outcomes, satisfaction, efficiency, and attitudes: a systematic review. Annals of internal medicine, 2013. 159(10): p. 677687.

31. Liu, J., et al., Patient satisfaction with electronic medical/health record: a systematic review. Scandinavian journal of caring sciences, 2013. 27(4): p. 785-791.

32. Sorondo, B., et al., Using a Patient Portal to Transmit Patient Reported Health Information into the Electronic Record: Workflow Implications and User Experience. eGEMs, 2016. 4(3).

33. Neuner, J., et al., Meaningful use and the patient portal: patient enrollment, use, and satisfaction with patient portals at a later-adopting center. American Journal of Medical Quality, 2015. 30(2): p. 105-113.

34. Amante, D.J., et al., A systematic review of electronic portal usage among patients with diabetes. Diabetes technology \& therapeutics, 2014. 16(11): p. 784-793.

35. Mishuris, R.G., et al., Barriers to patient portal access among veterans receiving home-based primary care: a qualitative study. Health Expectations, 2015. 18(6): p. 2296-2305.
36. Sorondo, B., et al., Patient Portal as a Tool for Enhancing Patient Experience and Improving Quality of Care in Primary Care Practices. eGEMs, 2016. 4(1).

37. Ralston, J.D., et al. Use and satisfaction of a patient Web portal with a shared medical record between patients and providers. in AMIA Annual Symposium Proceedings. 2006. American Medical Informatics Association.

38. Tannery, N.H., et al., Impact and user satisfaction of a clinical information portal embedded in an electronic health record. Perspectives in Health Information Management/AHIMA, American Health Information Management Association, 2011. 8(Fall).

39. Tuil, W.S., et al., Empowering patients undergoing in vitro fertilization by providing Internet access to medical data. Fertility and sterility, 2007. 88(2): p. 361-368.

40. Schnipper, J., et al., Design and implementation of a web-based patient portal linked to an electronic health record designed to improve medication safety: the Patient Gateway medications module. Journal of Innovation in Health Informatics, 2008. 16(2): p. 147-155.

41. Johnson, A.J., et al., Access to radiologic reports via a patient portal: clinical simulations to investigate patient preferences. Journal of the American College of Radiology, 2012. 9(4): p. 256-263.

42. Koppel, R. and C.U. Lehmann, Implications of an emerging EHR monoculture for hospitals and healthcare systems. Journal of the American Medical Informatics Association, 2014: p. amiajnl2014-003023.

43. Fürnkranz, J., A study using n-gram features for text categorization. Austrian Research Institute for Artifical Intelligence, 1998. 3(1998): p. 1-10.

44. Le, Q. and T. Mikolov. Distributed representations of sentences and documents. in Proceedings of the 31st International Conference on Machine Learning (ICML-14). 2014. 